\title{
Natural Products from Nocardia and Their Role in Pathogenicity
}

\author{
Alicia Engelbrecht ${ }^{a} \quad$ Hamada Saad $^{a, b}$ Harald Gross $^{a} \quad$ Leonard Kaysser $^{a, c}$ \\ aDepartment of Pharmaceutical Biology, University of Tübingen, Tübingen, Germany; ${ }^{\text {b Department of }}$ \\ Phytochemistry and Plant Systematics, Division of Pharmaceutical Industries, National Research Centre, Cairo, \\ Egypt; 'Institute for Drug Discovery, University of Leipzig, Leipzig, Germany
}

\section{Keywords}

Nocardia $\cdot$ Natural products · Pathogenicity

\begin{abstract}
Nocardia spp. are filamentous Actinobacteria of the order Corynebacteriales and mostly known for their ability to cause localized and systemic infections in humans. However, the onset and progression of nocardiosis is only poorly understood, in particular the mechanisms of strain-specific presentations. Recent genome sequencing has revealed an extraordinary capacity for the production of specialized small molecules. Such secondary metabolites are often crucial for the producing microbe to survive the challenges of different environmental conditions. An interesting question thus concerns the role of these natural products in Nocardia-associated pathogenicity and immune evasion in a human host. In this review, a summary and discussion of Nocardia metabolites is presented, which may play a part in nocardiosis because of their cytotoxic, immunosuppressive and metal-chelating properties or otherwise vitally important functions. This review also contains so far unpublished data concerning the biosynthesis of these molecules that were obtained by detailed bioinformatic analyses.

(c) 2021 The Author(s)

Published by S. Karger AG, Basel
\end{abstract}

\section{Introduction}

Infectious diseases caused by bacteria, fungi, parasites or viruses are still a significant cause of death worldwide [Dye, 2014]. Interestingly, the therapeutic agents to combat such infections are also predominantly derived from microorganisms. One of the most important producers of small molecules with pharmaceutical values, such as antibacterial, antiviral, anticancer, antiparasitic, and immunosuppressing activities, are filamentous Actinobacteria [Mann, 2001; Barka et al., 2016; Lee et al., 2020]. The biosynthesis of these natural products is governed by defined sets of genes organized in biosynthetic gene clusters (BGCs), encoding, e.g., polyketide synthases (PKS), nonribosomal peptide synthetases (NRPS) and hybrid NRPS/ PKS machineries. Genes that mediate expression control, self-resistance or export are typically clustered together with these biosynthetic genes in the BGCs [Walsh and Fischbach, 2010; Medema et al., 2015]. Such compounds, produced as secondary metabolites, are often crucial elements in bacterial survival strategies, e.g., as "defense weapons" against other microorganisms or within a host organism. Additionally, these molecules can mediate inter-species and intra-species communication or provide an advantage in nutrient acquisition [Netzker et al., 2018].
C 2021 The Author(s).

Published by S. Karger AG, Basel

This is an Open Access article licensed under the Creative Commons Attribution-NonCommercial-4.0 International License (CC BY-NC) (http://www.karger.com/Services/OpenAccessLicense), applicable to the online version of the article only. Usage and distribution for commercial purposes requires written permission.
Correspondence to:

Leonard Kaysser, leonard.kaysser@ uni-leipzig.de 
Nocardia spp. are filamentous Actinobacteria of the order Corynebacteriales. They are closely related to the genera Corynebacterium and Mycobacterium, but particularly to the genus Rhodococcus. They primarily form mycelia, but can also fragment into rod- to coccoidshaped bacteroid non-motile elements [Dhakal and Sohng, 2015]. A characteristic feature of Nocardia spp. is that they contain tuberculostearic acids in their cell wall, similar to members of the genus Mycobacterium. However, in contrast to mycobacteria, Nocardia spp. produce short-chain (40- to 60-chain) mycolic acids and usually exhibit branching on Gram staining [Brown-Elliott et al., 2006]. Nocardia are often found in organic-rich soil as ubiquitous saprophytes. But most prominently, they are recognized as human opportunistic pathogens. Therefore, they have mostly been isolated from human tissue, and comparably few strains were isolated from environmental samples, such as soil and water [McNeil and Brown, 1994]. In general, immunocompromised patients are affected by nocardiosis with a high mortality rate. Nevertheless, cases in immunocompetent patients have also been reported [Wilson, 2012]. Numerous different strains of Nocardia have been identified, many of which are described as infectious to humans and animals. To date, more than 50 Nocardia species are considered clinically significant [Conville et al., 2018]. The most prevalent human pathogens are Nocardia farcinica, Nocardia asteroides type VI (Nocardia cyriacigeorgica), Nocardia brasiliensis, the Nocardia nova complex, Nocardia abscessus and the Nocardia transvalensis complex [Brown-Elliott et al., 2006]. Usually, Nocardia cause localized cutaneous or pulmonary infections. From the infection site, the bacteria can disseminate throughout the whole body, leading to systemic forms of nocardiosis, which often includes severe brain infections. Nocardia spp., in general, have been studied for a long time, but most of the studies have focused on the characterization and taxonomic classification of new isolates as well as host pathophysiology [Beaman and Beaman, 1994; Brown-Elliott et al., 2006]. In particular because of their clinical importance, many Nocardia genomes were sequenced within the last decade. Surprisingly, these efforts showed an extraordinary potential for the production of diverse secondary metabolites for most Nocardia strains, rivalling better-known genera such as Amycolatopsis [Männle et al., 2020]. Although pathogenic bacteria have been recognized as a source for natural products drug discovery, they remain largely untapped and understudied [Maglangit et al., 2020]. More recently, some Nocardia strains have moved into focus as producers of compounds with pharmaceuti- cal value regarding their immunosuppressant, antimicrobial, cytotoxic or antifungal bioactivity, i.e., N. brasiliensis, N. abscessus, N. transvalensis, Nocardia terpenica and Nocardia pseudobrasiliensis [Shigemori et al., 1998; Mikami, 2007; Luo et al., 2014b; Dhakal et al., 2019]. However, because most Nocardia spp. produce secondary metabolites only in trace amounts, it was found difficult to isolate and produce the desired compounds for pre-clinical and clinical characterization and widespread therapeutic use. Metabolic engineering approaches and synthetic biological tools were developed to overcome the bottleneck in terms of cost-effectiveness and scale-up possibilities paving a route towards commercial application and large-scale production. In addition, most Nocardia spp. are biosafety level 2 organisms, and genetic manipulation in the native producer can thus be tedious and time consuming. Therefore, heterologous expression of BGCs has emerged as a key strategy to gain access to the promising secondary metabolite gene cluster and to reach titers of industrial levels [Wohlleben et al., 2012; Brown and Dawson, 2015; Baltz, 2016; Dhakal et al., 2016b; Luo et al., 2016; Katz et al., 2018]. As an example, heterologous expression and optimizations of the biosynthetic pathway for brasilicardins have been employed in Amycolatopsis. This resulted in the increased production of $\mathrm{BraC}$ and the BraC-aglycon by $27 \%$, a titer that is comparable to production from the native producer $N$. terpenica IFM0406 [Schwarz et al., 2018a; Schwarz et al., 2018b]. Furthermore, nargenicin A1 production has been successfully enhanced up to 24-fold in comparison to the control strain by the application of a combined overexpression and precursor feeding strategy [Dinesh et al., 2012; Dhakal et al., 2015; Dhakal et al., 2016a].

Many Nocardia strains combine properties from their sister genus Rhodococcus and the slightly more distantly related genus Mycobacterium, reflecting their need to survive in different ecological settings. Similar to Rhodococci, Nocardia spp. are able to produce diverse hydrolytic enzymes and possess the metabolic versatility to degrade complex organic compounds [Luo et al., 2014a; Luo et al., 2014b]. This allows them to live successfully as highly flexible saprophytes in challenging, e.g., oil- or industrial waste-contaminated environments. On the other hand, Nocardia strains can cause pulmonary forms of nocardiosis that resemble tuberculosis in most clinical symptoms and radiological manifestations [Duggal and Chugh, 2020]. Nocardia primarily infect the lungs or cutaneous and lymphocutaneous tissues of immunocompromised patients. Such opportunistic behaviour is also known from pathogenic non-tuberculous mycobacteria, includ- 
Fig. 1. Natural products from Nocardia spp. with immunosuppressant activity.

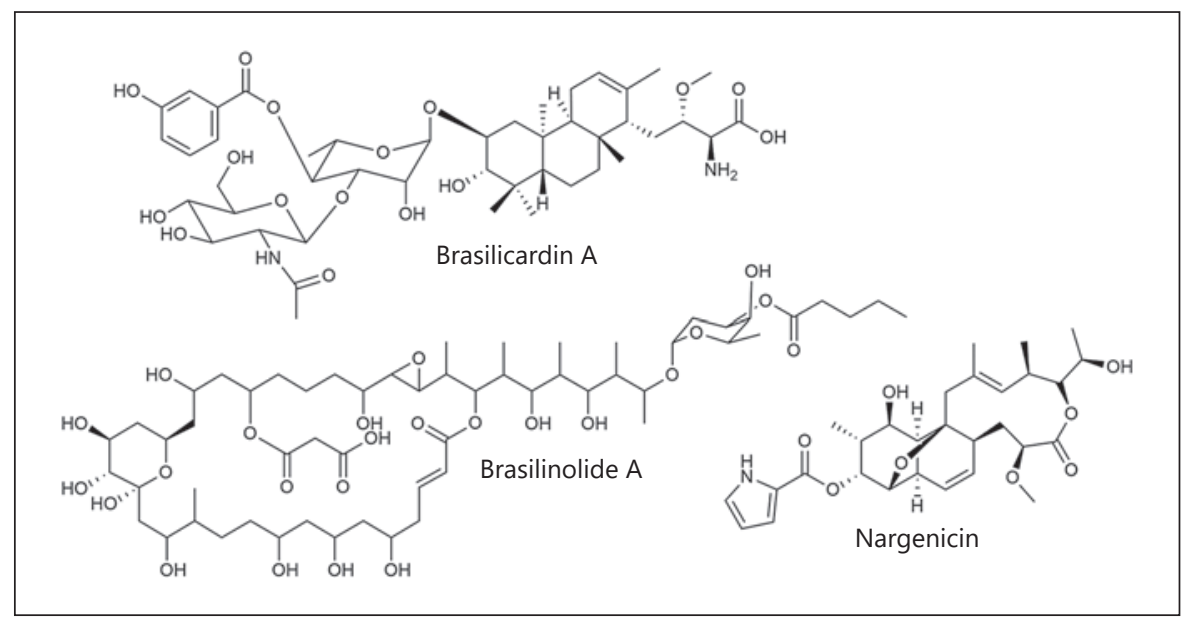

ing the Mycobacterium avium complex, Mycobacterium kansasii, Mycobacterium abscessus and Mycobacterium ulcerans. The common aspects of Nocardia and Mycobacterium pathogenesis have been attributed to a shared cell wall physiology containing layers of mycolic acid and arabinogalactan as well as more general virulence factors, e.g., catalase and superoxide dismutase enzymes, invasion-like proteins, phospholipase $\mathrm{C}$, haemolysin and the cord factor [Beaman and Beaman, 1994; Vera-Cabrera et al., 2013; Zoropogui et al., 2013; Ji et al., 2020]. However, major parts of Nocardia infections remain poorly understood, including strain-specific virulence and progression of nocardiosis. It is noteworthy that a number of molecules, which are considered to be essential for survival and pathogenicity of Mycobacteria, are synthesized by biosynthetic machineries, which are usually associated with the secondary metabolism, i.e., PKS and NRPS. The main examples are mycolate-, phthiocerol-, tetrapeptideand mycoketide-based cell wall glycolipids, various siderophores and the toxin mycolactone [Portevin et al., 2004; Stinear et al., 2004; Chopra et al., 2008; Matsunaga and Sugita, 2011; Yu et al., 2012]. Recently, the analysis of the first Nocardia genome sequences showed a high diversity of PKS- and NRPS-containing gene clusters, some of them appear to be conserved in all analysed strains, some of them are unique [Komaki et al., 2014]: the number of secondary metabolite pathways in Nocardia species is roughly similar to Streptomyces with an average of 36 BGCs per genome [Doroghazi and Metcalf, 2013; Männle et al., 2020]. How the encoded chemistry exactly contributes to the general and strain-specific pathogenicity of Nocardia spp. is a focus of ongoing investigations. In the current review, Nocardia metabolites with cytotoxic, im- munosuppressive, metal-chelating properties or vitally important functions, which may play a part in nocardiosis, will be summarized and discussed. So far unpublished data concerning the biosynthesis of these molecules obtained by detailed bioinformatic analysis will also be included.

\section{Metabolites with Cytotoxic and Immunosuppressive Properties}

For a long time, it has been speculated that cytotoxic and immunosuppressive properties of Nocardia secondary metabolites may play a role in infection, immune evasion and clinical manifestation of the disease. Mikami and co-workers have been the first to systematically exploit clinical Nocardia isolates as a source of pharmaceutically interesting natural products [Mikami, 2007]. Based on this assumption and by similar efforts of other research groups, a number of bioactive molecules could be isolated and characterized.

In the realm of immunosuppressants, $N$. terpenica IFM 0406 (formerly referred to as N. brasiliensis) was found to biosynthesize brasilicardins (A-D) as remarkable immunosuppressive entities. This unique molecular family is characterized by featuring a diterpene skeleton decorated with $\mathrm{N}$-acetylglucosamine (GlcNAc), L-rhamnose, pyruvate and 3-hydroxybenzoate (3-HBA) units [Shigemori et al., 1998]. Outstandingly, brasilicardin A (shown in Fig. 1) selectively revealed antitumour activity with a striking pattern of differential cytotoxicity $\left(\mathrm{IC}_{50}=\right.$ $0.22-100 \mu \mathrm{g} / \mathrm{mL}$ ) against a broad panel of various tumour cell lines [Komaki et al., 1999; Komatsu et al., 2005]. Moreover, via a mouse mixed lymphocyte reaction as a simulating setup for allograft rejection, brasilicardin A 
exhibits comparable $\mathrm{IC}_{50}$ immunosuppressive readings to cyclosporine A, slightly lower than the ones of tacrolimus, thereby employing a possible new strategy of immunosuppression that modulates the amino acid transporter system L of T-lymphocytes [Usui et al., 2006]. In contrast, the immunosuppressive evaluation of brasilicardins $\mathrm{B}$ and $\mathrm{C}$ dropped approximately 50 times compared to brasilicardin A, while brasilicardin D did not afford such readings, pinpointing the necessity of the methoxy group at C-16, GlcNAc and 3-HBA for immunosuppressive activity. Due to the extraordinary potency of brasilicardins as promising immunosuppressants and the urgency to glean additional biological and pharmacological studies, many total synthetic trials were recalled to successfully de novo construct this molecular family to overcome their limited availability from natural sources [Anada et al., 2017]. Biosynthetically, the implementation of $D-\left[1-{ }^{13} \mathrm{C}\right]$ glucose in an incremental manner at C2, C6, C11, C15, C19, C21, C22 and C23 in the perhydrophenanthrene skeleton validated that geranylgeraniol was the precursor of the diterpene. Moreover, the amino acid moiety was found to possibly be derived from $\left[3-{ }^{13} \mathrm{C}\right]$ pyruvate via the non-mevalonate pathway. Cloning and inactivating a geranylgeranyl diphosphate synthase enabled the identification of the responsible gene cluster [Shigemori et al., 1999; Hayashi et al., 2008]. In a follow-up investigation, Schwarz et al. [2018a] filled the gaps of the putative roles of some genes located within the cluster. $\mathrm{Bra} 0$ as a putative dioxygenase in cooperation with Bra11 is envisioned to be responsible for methoxylation at $\mathrm{C} 16$ of the brasilicardins backbone. Furthermore, Bra12 was found to act as a vital positive regulator for the brasilicardin production, pinpointing an essential consideration for any future biotechnological setup of producing such entities.

The retrieval of brasilinolides $(\mathrm{A}-\mathrm{C})$ as multifaceted bioactive macrolides from $N$. terpenica (formerly $N$. brasiliensis) IFM 0406 provided further proof of the fascinating molecular chemotypes that Nocardia can assemble. Structurally, these architectures frame a glycosylated 32-membered polyhydroxy macrolactone with a tetrahydropyran hemiketal ring entrenched within the macrocycle and 2-deoxy-L-fucose (2dF) as a deoxysugar decoration. Biologically, this molecular family was found to address bio-versatile purposes as immunosuppressive, antitumour and antifungal bioactivities [Hideyuki et al., 1996]. Interestingly, brasilinolide A (shown in Fig. 1), besides being a potent immunosuppressant, displayed inherited chemo- and bio-tractability via its favourable physicochemical properties accompanied with a notable low cytotoxicity index. Differently, brasilinolide B did not disclose any immunosuppressive effectiveness but antifungal and antibacterial activities, which has been speculatively referred to the structural variations in the unusual deoxysugar moiety [Tanaka et al., 1997b; Mikami et al., 2000]. Lacking both the $2 \mathrm{dF}$ and macrolide $(\mathrm{C} 23-\mathrm{OH})$ motifs, brasilinolide $\mathrm{C}$, in contrast to brasilinolide $\mathrm{A}$, showed anticancer activity towards a murine lymphoma cell line. However, the suppressive effect on mouse mixed lymphocytes was lost, which was structurally attributed to the 23-O-malonyl and 3'-O-pentanoyl groups' significance in the immunosuppression [Komatsu et al., 2004]. In light of the scaffold biosynthesis of brasilinolides and their various impressive biological properties, the possible engineering of their type I modular PKS and decorating enzymes (C37-O-glycosylation, C23-O-[alkyl]malonyl acid esterification, C28-29 epoxidation, C16-hydroxylation and $\mathrm{O}$-acylation/methylation of the sugar moiety) can be harnessed as a rationale for leveraging such bioactive chemical space and other related macrolides to be appended with different structural elements like tunable glycosyl patterns [Chiu et al., 2016].

Nargenicin (shown in Fig. 1) is a highly unusual polyketide macrolactone containing a rare oxa-bridged decalin core as its key structural feature [Celmer et al., 1980]. It has been isolated from a number of different $\mathrm{No}$ cardia species, e.g., Nocardia sp. CS682, N. argentinesis and $N$. arthritidis, but the genetic basis for the production of nargenicin has remained unknown until recently. Pidot et al. [2019] have identified the BGC and the ironand $\alpha$-ketoglutarate-dependent dioxygenase responsible for the formation of the ether bridge. Nargenicin targets the bacterial replicative DNA polymerase DnaE, but also inhibits cell proliferation and induces cell differentiation in acute myeloid leukemia cell lines, if co-administered with 1,25-dihydroxyvitamin $\mathrm{D}_{3}$ or all-trans-retinoic acid [Kim et al., 2009]. Additionally, it has been reported to attenuate lipopolysaccharide-induced inflammatory responses and shown to protect cells from tacrolimus-induced DNA damage and apoptosis [Yoo et al., 2009]. The latter activity was at least partially due to scavenging of reactive oxygen species and, hence, suppression of the mitochondrion-dependent apoptotic pathway [Park et al., 2019]. Very recently, a nargenicin A1 derivative was identified as a potent anticancer agent [Dhakal et al., 2020]. It was shown to inhibit angiogenesis by downregulating endothelial VEGF/VEGFR2 signalling and the tumoural HIF-1 $\alpha$ /VEGF pathway [Han et al., 2020].

In complement to the intriguing immunosuppressive entities that Nocardia can offer, a wide chemical space with cytotoxic properties was validated as well. Examples 


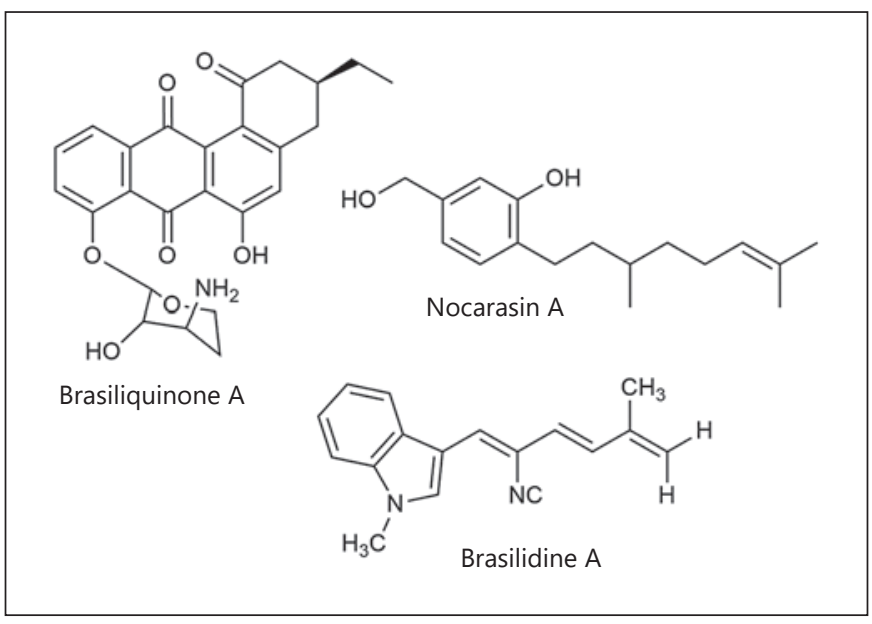

Fig. 2. Structures of representative cytotoxically active compounds.

of Nocardia-specific anthracycline antibiotics are nothramycin, SO-75R1 and the nocardicyclins [Mikami et al., 1992; Tanaka et al., 1997a; Momose et al., 1998]. In vitro antitumour activity of nocardicyclin A against the P388 leukemia cell line and its multi-drug-resistant derivative P388/ADR was shown [Tanaka et al., 1998]. DNA-damaging agents, such as anthracyclines, are promising candidate drug leads for cancer therapy, but their use is limited by low production titer, dose-related toxicities (e.g., cardiotoxicity), as well as development of drug resistance. These problems are still essential to overcome to provide novel therapeutic options [Bauermeister et al., 2016]. Further cytotoxic compounds from Nocardia spp. include the benz[a]anthraquinone antibiotics brasiliquinones A-D (shown in Fig. 2), produced by N. brasiliensis IFM 0089. Brasiliquinones were active against L1210 and $\mathrm{KB}$ tumour cells in vitro with $\mathrm{IC}_{50}$ values ranging from 0.55 to $3.4 \mu \mathrm{g} / \mathrm{mL}$ [Nemoto et al., 1997; Tsuda et al., 1999]. Moreover, brasiliquinone $\mathrm{C}$ showed strong inhibitory activity against the epidermal growth factor (EGF) receptor kinase and some activity against c-erbB-2 kinase, involved in cell proliferation. Brasilidine A (shown in Fig. 2) is an isonitrile-containing indole alkaloid which was obtained from the same N. brasiliensis strain. The molecule showed cytotoxicity against several tumour cell lines, e.g., the multidrug-resistant P388/ADM ( $\left.\mathrm{IC}_{50}, 0.56 \mu \mathrm{g} / \mathrm{mL}\right)$ and $\mathrm{CHO} / \mathrm{MDR}\left(\mathrm{IC}_{50}, 3.43 \mu \mathrm{g} / \mathrm{mL}\right.$ ) [Kobayashi et al., 1997]. $N$. brasiliensis IFM 0667 produces the geranylated benzenoid metabolites nocarasins A-C (shown in Fig. 2), which showed considerably cytotoxicity against human leukemia cell lines in vitro, with $\mathrm{IC}_{50}$ values of $0.91,0.51$ and
$0.60 \mu \mathrm{g} / \mathrm{mL}$, respectively [Tsuda et al., 1999]. These compounds exhibit promising bioactivity in vitro, but whether they represent good drug candidates for further clinical development remains to be explored.

Driven by the pathogenicity of several members of the genus Nocardia, Nocardia tenerifensis IFM $10554^{\mathrm{T}}$ was cocultured with the mouse macrophage-like cell line J774.1, in an elegant attempt to replicate the initial infection state to induce the secondary metabolism. Interestingly, nocarjamide (shown in Fig. 3), a cyclic nonapeptide with Wnt signal-alleviating activities, was exclusively expressed under these conditions, exemplifying the need of non-classical coculture setups to unlock the silent biosynthetic machineries of Nocardia [Hara et al., 2018]. The identification of such Wnt signal-modulating secondary metabolites might contribute to untangling Nocardia's pathogenicity, counting on the involvement of these signalling cascades in numerous crucial processes, such as the differentiation/proliferation of eukaryotic cells and various disease-underlying mechanisms like osteoporosis-pseudoglioma syndrome and Parkinson's ailment [Hara et al., 2018]. Although the encoding BGC for nocarjamide was not identified, it could be speculated that such chemistry derives from an NRPS assembly line. We have recently reported on a bioinformatic survey of the biosynthetic capacity of Nocardia spp. with a focus on secondary metabolites [Männle et al., 2020]. A revisit of our original data while preparing the current article revealed a putative biosynthetic pathway for the production of a nocarjamide-like compound in $N$. tenerifensis DSM 44704 (syn. IFM 10554). An overview of the gene cluster analysis is shown in Figure 4. The respective gene cluster encodes an NRPS machinery of nine modules featuring epimerase domains in modules 6 and 7 and methyltransferase domains in modules 3,4 and 9. The A-domain specificities for the first and last domains are predicted to be for threonine and valine, respectively. Such properties would perfectly match the required functionalities to assemble the L-Thr-L-Val-L-NmetLeu-L-NmetPhe-L-LeuD-Phe-D-Val-L-Ala-L-NmetVal nocarjamide peptide chain. Intriguingly, similar BGCs were found in several other Nocardia strains, e.g., N. brasiliensis ATCC 700358, Nocardia vulneris W9851, Nocardia sp. CS682 and Nocardia suismassiliense S-137. This finding, together with the specific conditions under which nocarjamide is produced, suggests a potential role in Nocardia pathogenesis. Still, further experiments are required to firmly establish the presumed genes-to-molecule link.

Another approach to unlock the hidden Nocardia chemistry was followed by the Khosla group. They were 
Fig. 3. Recently identified bioactive molecules isolated from Nocardia spp., NOCAP (NOCardiosis-Associated Polyketide).

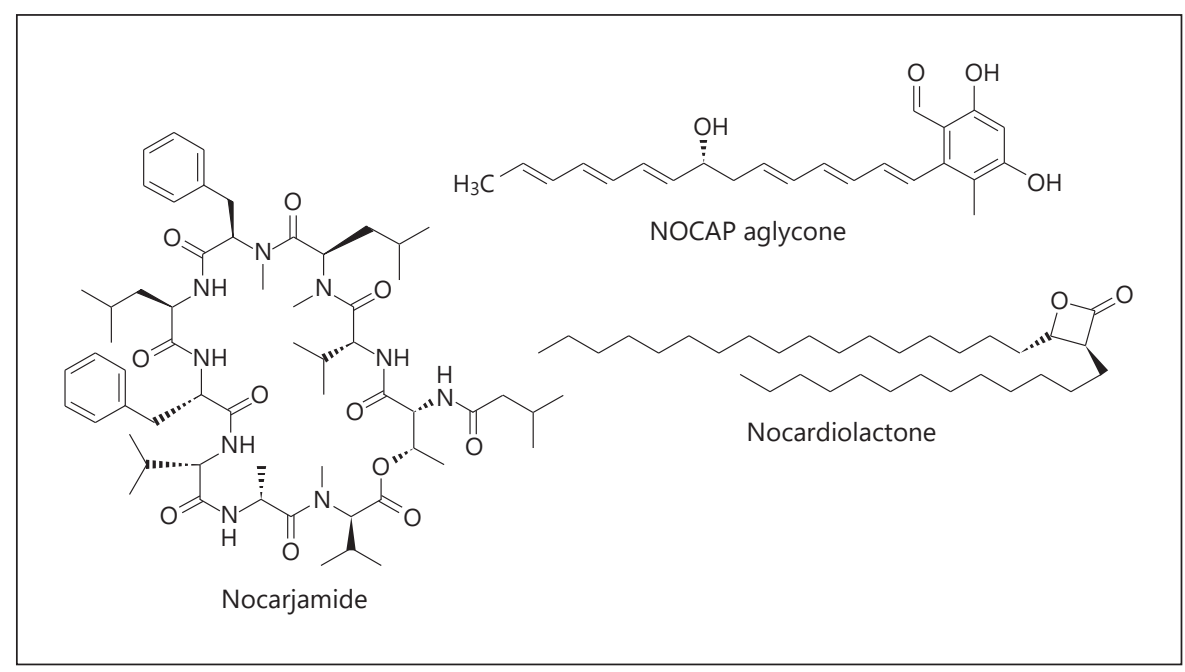

able to completely reconstitute and deorphanize a 3-MDa trans-AT PKS system that is predominantly found in clinical Nocardia isolates. The PKS was hence termed nocardiosis-associated polyketide synthase (NOCAP) [Kuo et al., 2016]. They were the first to describe the full in vitro reconstitution of an assembly line PKS that mainly contains trans-AT modules. The thereby synthesized compound consists of a substituted resorcylaldehyde moiety linked to a 15-carbon chain with 2 conjugated all-trans trienes separated by a stereogenic hydroxyl group. This molecule likely represents the aglycon of a yet to be discovered natural product which would be decorated with a 6-deoxy sugar (shown in Fig. 3). Further investigations of its biological role are underway [Yuet et al., 2020].

\section{Putative Components of the Cell Envelope}

Nocardia spp. encode a remarkable number of comparably simple pathways driven by ketosynthase biochemistry. One such example is the gene cluster for the biosynthesis of nocardiolactones (shown in Fig. 3) which has been found in 23 isolates [Mikami et al., 1999; Robinson et al., 2020]. An NltA/NltB heterodimer of ketoacyl-ACP synthase III (KASIII; FabH) homologs catalyzes the "head-to-head" Claisen condensation of two long-chain acyl-CoAs. Subsequent reduction by NltD generates a dialkyl $\beta$-hydroxy acid which is converted by the adenylateforming enzyme NltC to a di-alkyl $\beta$-lactone product. Such $\beta$-lactone synthetases were associated with the formation of various small molecules that act as inhibitors of hydrolytic enzymes [Wolf et al., 2017; Robinson et al., 2019]. A similar set of enzymes, for instance, is encoded in the BGC for lipstatin: LstA-D [Hochuli et al., 1987; Bai et al., 2014]. Whereas lipstatin is an acylated nocardiolactone derivative with potent activity against the pancreatic lipase, other $\beta$-lactone-containing compounds are inhibitors of proteases, e.g., the proteasome [Kaysser, 2019]. Given their lipophilic nature, it is likely that nocardiolactones are components of the bacterial cell envelope and might thus contribute to the interaction with the host during Nocardia infections. Notably, the respective pathway has been found to cumulate in clinically relevant $\mathrm{No}$ cardia strains.

In addition, Nocardia genomes are rich in monomodular type I PKS. The clinically important pathogen N. cyriacigeorgica GUH-2, for example, harbours 5 BGCs with this organization (out of 19 predicted BGCs in total) [Zoropogui et al., 2013; Komaki et al., 2014]. Similar pathways in Mycobacterium tuberculosis were determined to participate in the synthesis of diverse surface-exposed glycolipids including the assembly of mycolic acids, mycocerosic acids and pthiocerols [Matsunaga and Sugita, 2011]. The most abundant of such glycolipids are trehalose- $6,6^{\prime}$-dimyco-late (TDM), as well as the pthiocerol containing phenolic glycolipid (PGL) (shown in Fig. 5). Mycolic acid-containing glycolipids are known to affect the host immune system, e.g. by stimulation of cellular and humoral immunity, granuloma formation and anti-tumour activity. TDM, also named the cord factor, has been linked to intracellular survival of virulent Nocardia strains, thereby constituting potential virulence mechanisms. This may include favoured uptake into macrophages by activating the alternative complement pathway without triggering respiratory burst. And it was shown in in vitro systems that TDM potentially inhibits 
N. tenerifensis IFM10554 nocarjamide

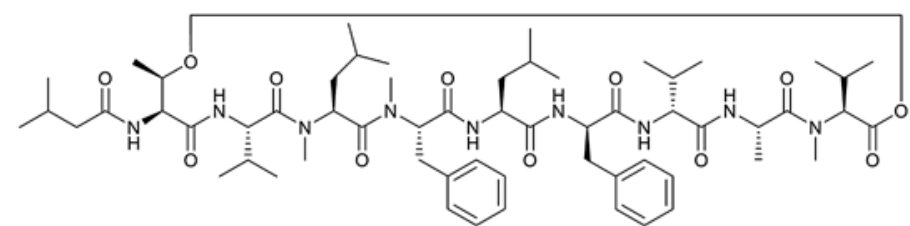

Iva L-Thr L-Val L-NmLeu L-NmPhe L-Leu D-Phe D-Val L-Ala L-NmVal

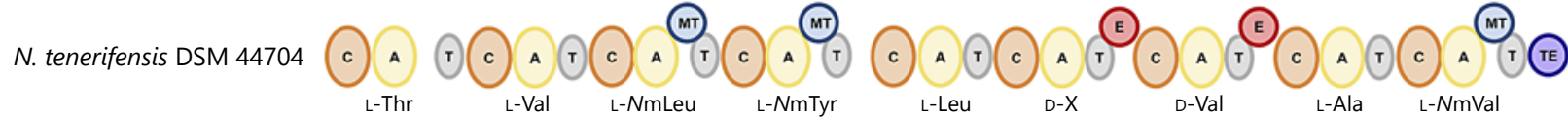

N. brasiliensis ATCC 70035 (C) A

N. vulneris W9851

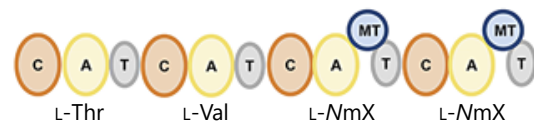

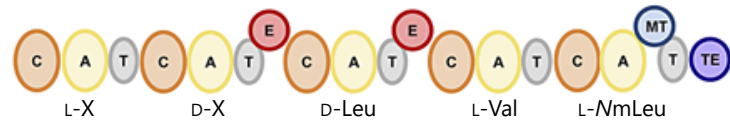

N. suismassiliense S-137

$$
\text { mLeu }
$$

(c) $\underset{\text { L-Thr }}{\mathrm{T}} \mathrm{C} \underset{\text { L-Val }}{\mathrm{A}} \mathrm{T} \underset{\text { L-NmLeu }}{\mathrm{A}} \mathrm{C} \underset{\text { L-NmTyr }}{\mathrm{A}} \mathrm{C}$

(c)

(MT) $(C) \underset{\text { L-NmTyr }}{\text { ATT }}$

C. $A$ L-Leu $\mathrm{C}$ D-Lys

a
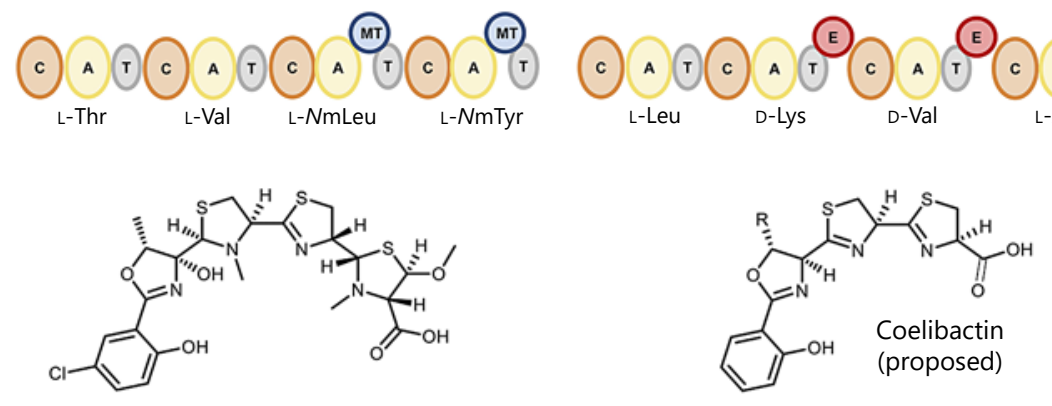

N. tenerifensis IFM10554 transvalencin A

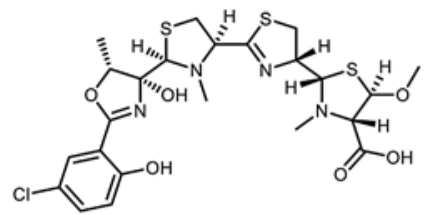

N. farcinica W6977

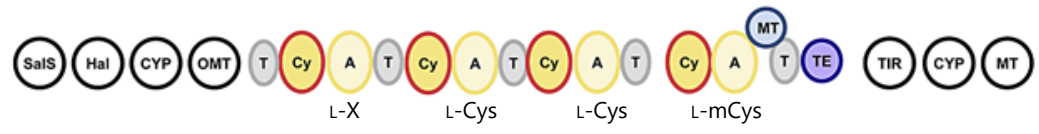

N. carnea NBRC 14403

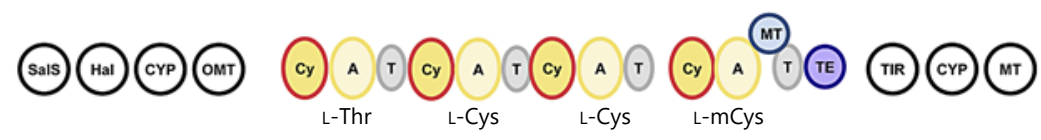

N. nova SH22a

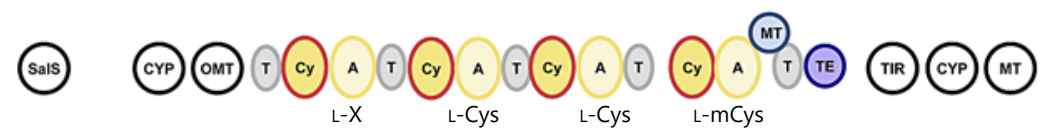

N. puris DSM 44599

(Sals) Haa

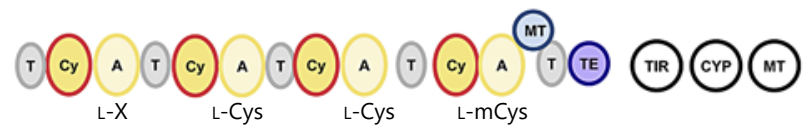

S. coelicolor A3(2)

b

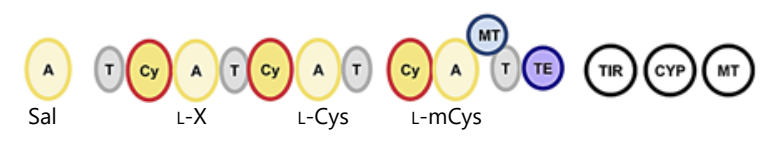

Fig. 4. Biosynthetic gene cluster analysis for the production of nocarjamide-like compound (a) and transvalencin A (b). 
Fig. 5. Glycolipids TDM (trehalose-6,6'DiMyco-late) and PGL (phenolic glycolipid).

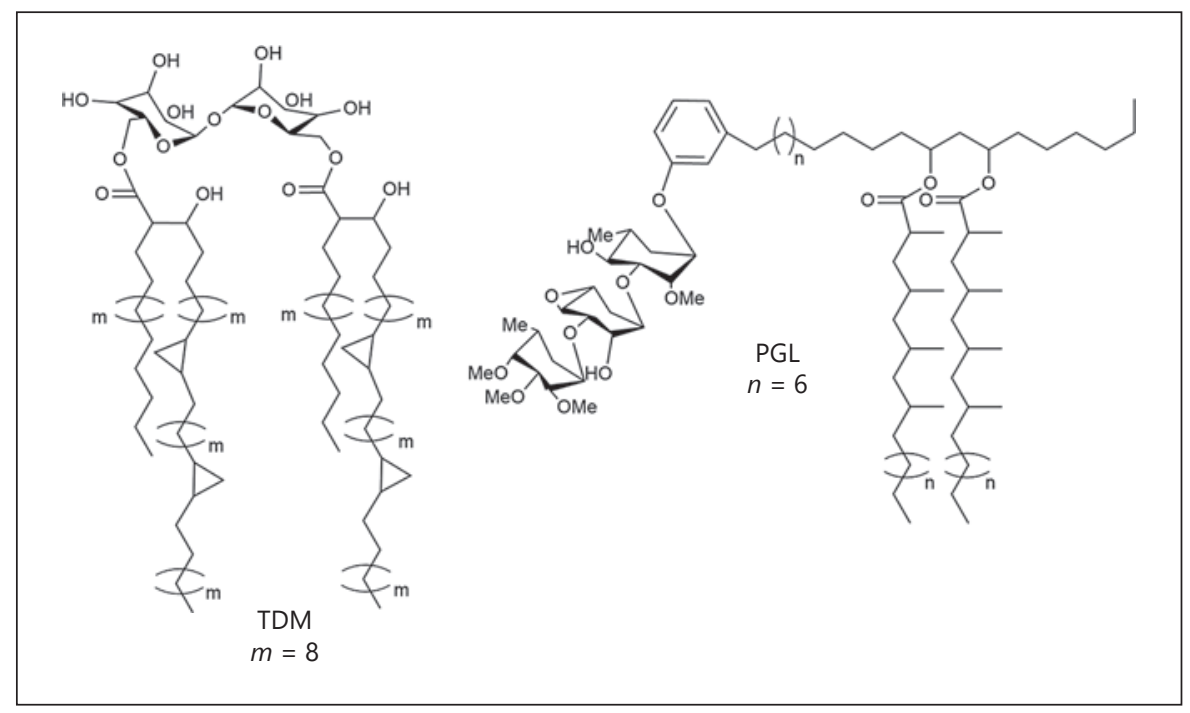

membrane fusion between the phagosome containing the bacterial cell and lysosomes of the host. Furthermore, TDM stimulates important effector cells in innate, early adaptive and both humoral and cellular adaptive immunity [Beaman, 1994; Ryll et al., 2001]. Indeed, the PKS cluster 1.1 of $N$. cyriacigeorgica GUH-2 is analogous to the mycolic acid BGC from M. tuberculosis and conserved in all Nocardia genomes [Männle et al., 2020; Blin et al., 2021]. Moreover, the type I PKS enzymes from clusters 1.10 and 1.13 show significant homology (48\%) to pthiocerol and pthioceranic acid synthases PpsC and Pks2, respectively [Blin et al., 2021]. This suggests that these BGCs could be involved in glycolipid biosynthesis, too. Remarkably, most sequenced Nocardia strains contain at least 1 such monomodular type I PKS cluster in addition to the mycolic-acid PKS. The PKS cluster 1.10 of N. cyriacigeorgica GUH-2 (and other Nocardia) also encodes a putative acyl-CoA dehydrogenase (ACAD) with homology to EpxF and MatG from the epoxomycin and matlystatin biosynthetic pathways, respectively [Schorn et al., 2014; Zettler et al., 2016; Leipoldt et al., 2017]. These enzymes are known to generate electrophilic groups for the production of potent small-molecule protease and proteasome inhibitors [Kaysser, 2019]. It could thus be speculated that the ACAD in cluster 1.10 might modify a CoA- or ACP-activated fatty acyl product of the encoded PKS, accordingly. Notably, N. cyriacigeorgica GUH-2 has been shown to inhibit proteasome activity and induce apoptosis in cells by a yet unidentified secreted small molecule [Loeffler et al., 2004; Barry and Beaman, 2007]. However, whether this activity correlates with product from cluster 1.10 has yet to be determined.

\section{Siderophores}

Since iron is an indispensable nutrient factor for most living systems, Nocardia spp. have developed their molecular entities to sequester such a valuable element from their diverse nutrient-limited niches [Dhakal et al., 2019]. Siderophores as Fe(III) scavengers are the most abundantly represented secondary metabolites from Nocardia with many biological properties. We conducted a first rough analysis within the antiSMASH BGC database [Blin et al., 2021] of relevant Nocardia strains, estimating that in general Nocardia genomes harbour on average at least two gene clusters for the production of siderophores. Iron is an essential element for pathogenic bacteria to survive and grow inside their human hosts. Therefore, the human body has invented a range of defence mechanisms that limit the availability of free iron to the invading pathogens. Most of the iron is tightly bound to specific proteins, such as haemoglobin, ferritin, or transferrin, thus severely restricting iron acquisition by the bacteria [Miethke and Marahiel, 2007]. To be able to access the iron pool inside a living system, microorganisms produce small molecules as high-affinity ferric iron chelators. Such siderophores form extracellular Fe(III) complexes with stabilities up to 300-times higher than, e.g., transferrin. Siderophores are thus considered important virulence factors for diverse pathogens including Mycobacterium spp. [Sritharan, 2000].

Over the last 25 years, suites of mycobactin-like siderophores, named nocobactins, have been disclosed from different pathogenic and non-pathogenic Nocardia spp. encompassing structurally variable subfamilies, e.g., the nocardimicins, amamistatins, BE-32030s, formobactin, 
brasilibactin, or terpenibactins [Dhakal et al., 2019; Chen et al., 2020; Männle et al., 2020]. Their architectures commonly frame two units of lysine, a C-terminal cyclic and a central acyclic one, usually decorated with $N^{\varepsilon}-\mathrm{OH}$ and $N^{\varepsilon}$-acyl functional groups. In addition, the 2-OH-phenyl(5/6)-methyl-oxazol(in)e moiety defines a further scaffold backbone unit. The variation in the substitution patterns of the oxazol(in)e, the phenyl residues and $N^{\varepsilon}$ of both lysine units in tandem with the fatty acid nature affords a broad panel of molecular congeners supporting their cognate producers to cope with their environments [Hoshino et al., 2011; Dhakal et al., 2019]. Biosynthetically, a non-linear assembly mechanism is hired to generate such entities recruiting three NRPS modules and one PKS module. Exemplified by the nocobactin NA split gene cluster, NbtF in tandem with a stand-alone A-domain NbtT are assumed to condensate salicylic acid with threonine which in turn is heterocyclized into an oxazole unit. NbtD in synergy with $\mathrm{NbtH}$ and $\mathrm{NbtG}$ incorporates the decorated $N^{\varepsilon}$-lysine into the backbone. In parallel, $\mathrm{NbtB}$ coupled with $\mathrm{NbtC}$ is envisioned to biosynthesize the 3-hydroxy fatty acid fragment which is subsequently esterified with the last tethered lysine, mediated by NbtD. Finally, NbtE propagates the skeleton with another morphed $N^{\varepsilon}$-hydroxylysine unit which undergoes $\varepsilon$-caprolactamization [Hoshino et al., 2011]. It could be shown that the diverse subfamilies of the nocobactin-like siderophores originate from one gene cluster family which is highly conserved in almost all Nocardia strains. The structural differences derive from subtle changes and additions in the genetic and thus biosynthetic repertoire of the respective pathways [Männle et al., 2020].

In addition to their biological potencies which were assessed in cytotoxicity, antitumour and antimuscarinic contexts, nocobactin-like siderophores are assumed to be correlated with Nocardia's pathogenicity during the progression of nocardiosis. Such an assumption was gleaned from their structural resemblance to the known virulence factor mycobactin from $M$. tuberculosis. Indeed, an $\Delta n b t E$-deficient mutant of $N$. farcinica IFM 10152 was attenuated cytotoxically towards murine macrophage-like J774A.1 cells, proposing an association between nocobactin NA (shown in Fig. 5) production and the observed virulence [Hoshino et al., 2011]. Recently, nocobactin NA was identified in a screening campaign, searching for small-molecule immune suppressors secreted by Nocardia species. Arai et al. [2020] found that this compound inhibits Notch signalling in a dose-dependent manner with $\mathrm{IC}_{50}$ values of up to $12.4 \mu \mathrm{M}$ and decreased the expression of hairy and enhancer of split 1 (Hes1) protein.
Notch is an important regulator of immune cell development and function, and interference by the pathogen may serve as an immune evasion mechanism.

Actinomycetes strain Acta 3026, which was found to belong to the genus Nocardia, produces two cytotoxic metabolites, nocardichelins A and B. Both compounds show inhibition of several human tumour cell lines with $\mathrm{GI}_{50}$ values in a low micromolar to nanomolar range. The nocardichelins represent a new group of siderophores by combining structural elements of mycobactin/nocobactin-type siderophores from mycobacteria or Nocardia spp. and hydroxamate-type siderophores. Nocardiachelins may thus facilitate similar virulence mechanisms [Schneider et al., 2007].

Besides nocobactins, further metal-chelating compounds have been isolated from Nocardia over the last decades. One example is JBIR-16 (shown in Fig. 6) from cultures of $N$. tenerifensis NBRC 101015 with structural resemblance to heterobactin from Rhodococcus erythropolis PR4 [Carrano et al., 2001; Mukai et al., 2009b; Bosello et al., 2013]. Notably, the genome of $N$. tenerifensis DSM 44704 (syn. NBRC 101015) encodes a heterobactin-like gene cluster with a trimodular NRPS system and a standalone adenylation (A) domain. The predicted product would be a X-Gly-Orn tripeptide decorated with dihydroxybenzoic (Dhb) acid moieties, perfectly fitting the JBIR-16 hOrn-Gly-Orn skeleton. The putative JBIR-16 BGC can be found in other Nocardia, e.g., N. brasiliensis ATCC 700358 and N. vulneris W9851. In the course of our genomic survey for secondary metabolite pathways in Nocardia, another gene cluster family was identified and also recognized as heterobactin-like, which is present in about one-third of the strains. Here, the putative pathways comprise a bimodular NRPS system with various and/or unknown specificities, a Dhb-specific A domain, oxidoreductases and a number of siderophore transporters. A corresponding compound has so far not been isolated, but given the widespread occurrence of the BGC, an important physiological function could be assumed. Another gene cluster family from Nocardia exhibits similarity to the pathway of the predicted metal-chelating molecule coelibactin from Streptomyces coelicolor A3 (2) [Bentley et al., 2002; Männle et al., 2020]. The proposed coelibactin structure consists of a phenoxazoline and two thiazoline moieties derived from the incorporation of salicylic acid (Sal), threonine or serine and two molecules of cysteine. The coelibactin-like BGCs from Nocardia spp. contains an additional Cys-specific NRPS module, another methyltransferase and, in some cases, a putative halogenase. Intriguingly, a compound that would match the 


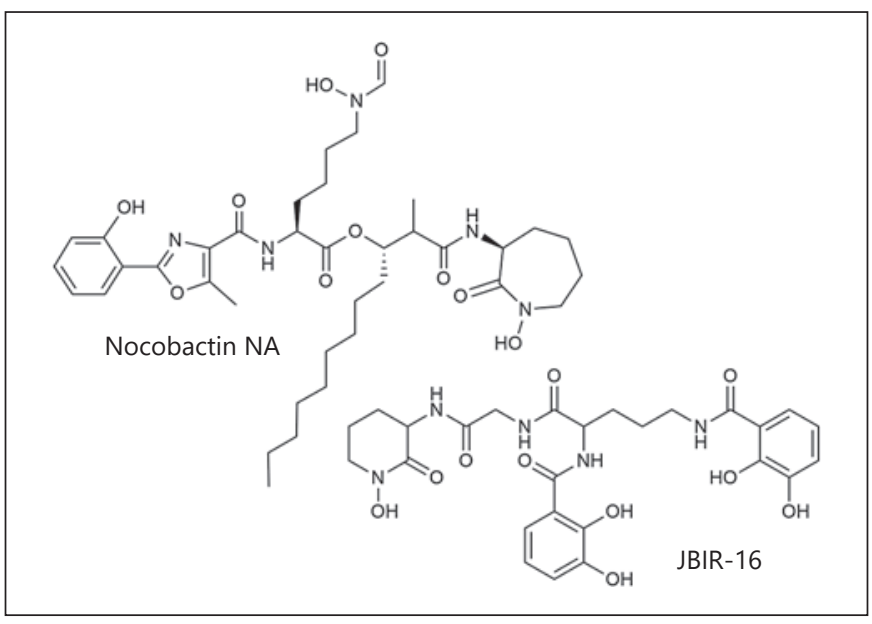

Fig. 6. Metal chelating compounds nocobactin NA and JBIR-16.

predicted product from this gene cluster family has been isolated previously: the thiazolidine zinc complex antibiotic transvalencin A produced by $N$. transvalensis IFM 10065 [Hoshino et al., 2004]. We would speculate that cluster 1.1 in N. farcinica W6977 and 1.10 in N. carnea NBRC 14403 may direct the formation of transvalencin A or at least a highly similar molecule (see Fig. 4) [Blin et al., 2021]. In contrast to the coelibactin BGC, the identified clusters in Nocardia do not feature a specific A domain for the activation of salicylic acid. However, all Nocardia strains that produce nocobactins contain such an enzyme to provide salicylic acid for nocobactin biosynthesis [Männle et al., 2020]. In fact, the respective gene, $n b t F$, is not co-located with the majority of the nocobactin BGC but can be found elsewhere on the genome in a small discrete BGC, also termed cluster II [Hoshino et al., 2011]. It might thus be possible that NbtF interacts with both the nocobactin and the putative transvalencin A pathway to channel the salicylic acid precursor and to control the siderophore profile in the respective Nocardia strains.

\section{Antibiotics}

Nocardia strains have been found to produce a variety of different antimicrobial compounds mainly as ribosomally synthesized and post-translationally modified peptides (RiPPs) or NRPS products. As such molecules are likely more important to establish the producing organism in its natural habitat in the environment than of clinical significance, we will only briefly summarize a few major examples. However, it has recently been shown by
Peschel and coworkers that antibiotic natural products may well play a role in disease-relevant competition processes in human microbiota [Zipperer et al., 2016].

Thiopeptides are macrocyclic RiPPs with several thiazole rings and multiple occurrences of dehydrated amino acid residues. The prominent class-defining feature of such a molecular family is the 6-membered nitrogenous ring that can exist in several oxidation states as a piperidine, dehydropiperidine or pyridine [Burkhart et al., 2017; Montalban-Lopez et al., 2020]. Nocardithiocin (shown in Fig. 7) is a thiocillin-similar thiopeptide produced by N. pseudobrasiliensis strain IFM 0757, structurally tailored with six thiazoles, two dehydrated amino acid residues besides a central heterocyclic frame. The highly bioactive peptide showed potent minimal inhibitory concentration (MIC) values at $0.025-6.25 \mu \mathrm{g} / \mathrm{mL}$ against clinical pathogens, such as rifampicin-resistant along with -sensitive M. tuberculosis strains [Mukai et al., 2009a; Sakai et al., 2015]. From Nocardia sp. ATCC 202099 , further substantially altered thiopeptides, the nocathiacins (shown in Fig. 7), were isolated with structural similarities to a nosiheptide indolic scaffold with distinctive functionalization, e.g., glycosylation with a rare sugar unit which improves their water solubility [Li et al., 2003; Bai et al., 2020]. Interestingly, nocathiacins (I-III) displayed an impressive in vitro nanomolar potency against a broad spectrum of gram-positive bacteria, including methicillin-resistant Staphylococcus aureus (MRSA), multi-drug resistant Enterococcus faecium (MREF), and penicillin-resistant Streptococcus pneumoniae (PRSP). More importantly, in a systemic $S$. aureus infection mice model, nocathiacins showed equivalent efficacy to vancomycin [Leet et al., 2003]. However, nocathiacins have not yet proceeded to clinical application, largely due to solubility issues. A wide range of chemical modifications were made on different moieties to increase the solubility. The thereby generated derivatives maintained good activity at least in vitro, but in vivo activities were largely disappointing [Brown and Dawson, 2015]. Nevertheless, the most promising compound LFF571 [LaMarche et al., 2012] has successfully completed a phase II clinical trial for treatment of Clostridium difficile infections [Mullane et al., 2015]. So far, no phase III trial has been reported.

A hybrid lipidated lanthipeptide, lipolanthine, was recently isolated from $N$. terpenica IFM 0406 by a bioactivity-guided strategy in synergy with genome mining efforts. Nocavionin (shown in Fig. 7) represents the first example of a lipidated ribosomally synthesized peptide featuring an unusual decarboxylated motif termed as avionin. Even though so far no antibacterial evaluations for 


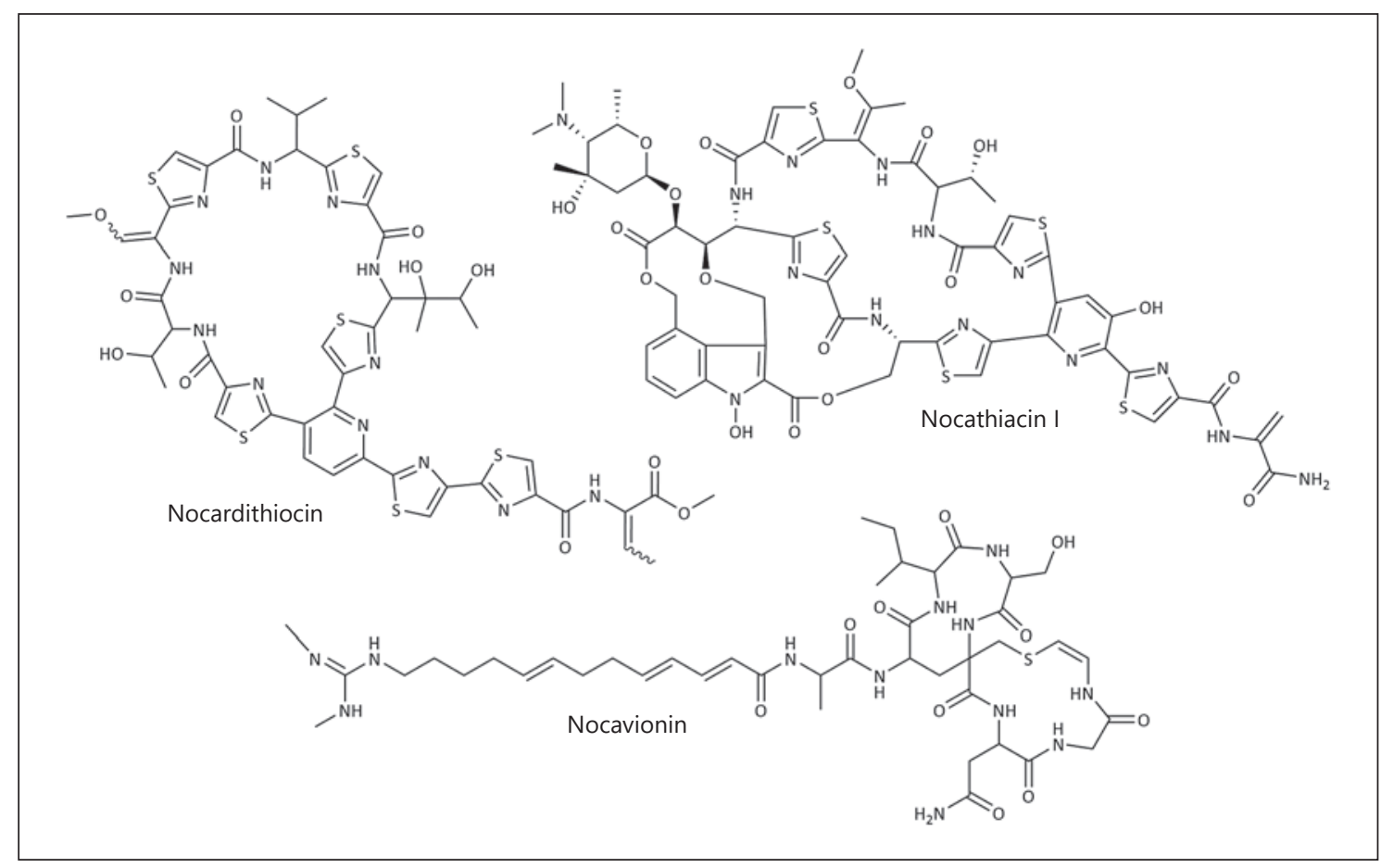

Fig. 7. Structures of recently identified antibiotically active molecules.

nocavionin have been reported, its structural variant microvionin exhibited strong antibacterial effects with MICs $<0.46$ and $0.15 \mu \mathrm{g} / \mathrm{mL}$ against MRSA and S. pneumoniae, respectively [Wiebach et al., 2018].

Nocardicins (A-B) from N. uniformis subsp. tsuyamanensis are the smallest representatives of NRPS-based compounds containing a monocyclic $\beta$-lactam ring, alongside an oxime and double $p$-hydroxyphenylglycine units. They exhibit moderate potency against a broad variety of gramnegative bacteria and some $\beta$-lactamase-resistant species. Unexpectedly, the in vivo readings of nocardicin A were higher than in vitro upon its administration to mice infected with gram-negative bacilli [Aoki et al., 1976; Hashimoto et al., 1976; Mine et al., 1977; Nishida et al., 1977]. Townsend and co-workers conducted several studies on nocardicin biosynthesis, leading to a detailed understanding of the respective biochemical mechanisms [Hosoda et al., 1977; Townsend and Brown, 1982; Townsend and Brown,1983; Townsend et al., 1983; Townsend and Salituro, 1984]. Genome sequencing revealed the nocardicin A BGC, in which the open reading frames to biosynthesize the nonproteogenic $p$-hydroxyphenylglycine precursor are arranged alongside the NRPS for the assembly [Gunsior et al., 2004; Davidsen et al., 2013].
Peptidolipin NA is a cyclic lipopeptide from the terrestrial N. asteroides in which cyclization is executed via an ester to an unusually long lipophilic tail. It was found to exert an antibiotic effect by interacting with the membrane lipid bilayers, generating ion-conducting pores. Recently, peptidolipins (B-F) were reported from a marine Nocardia strain WMMB215 with moderate bacteriostatic potency against MRSA [Maget-Dana et al., 1985; Wyche et al., 2012].

Furthermore, during our genomic and chemical exploration of Nocardia spp., we and others [Navarro-Muñoz et al., 2020] became aware that the genome of N. terpenica IFM 0406 contains the BGC coding for the outstanding anti-antibiotic detoxin (Fig. 8). Subsequent chemical analyses of the crude extract of IFM 0406, using high-resolution LC/MS and MS/MS experiments (Fig. 8a-f), confirmed that IFM 0406 is actually able to produce detoxin D1 and D3. The detoxin complex was originally isolated from Streptomyces spp. and is a selective antagonist of the antibiotic blasticidin S [Yonehara et al., 1968; Shimazu et al., 1981]. Thus, a subset of Nocardia species do not only produce antibiotics, they are also capable to antagonize the activity of antibiotics from other organisms. 


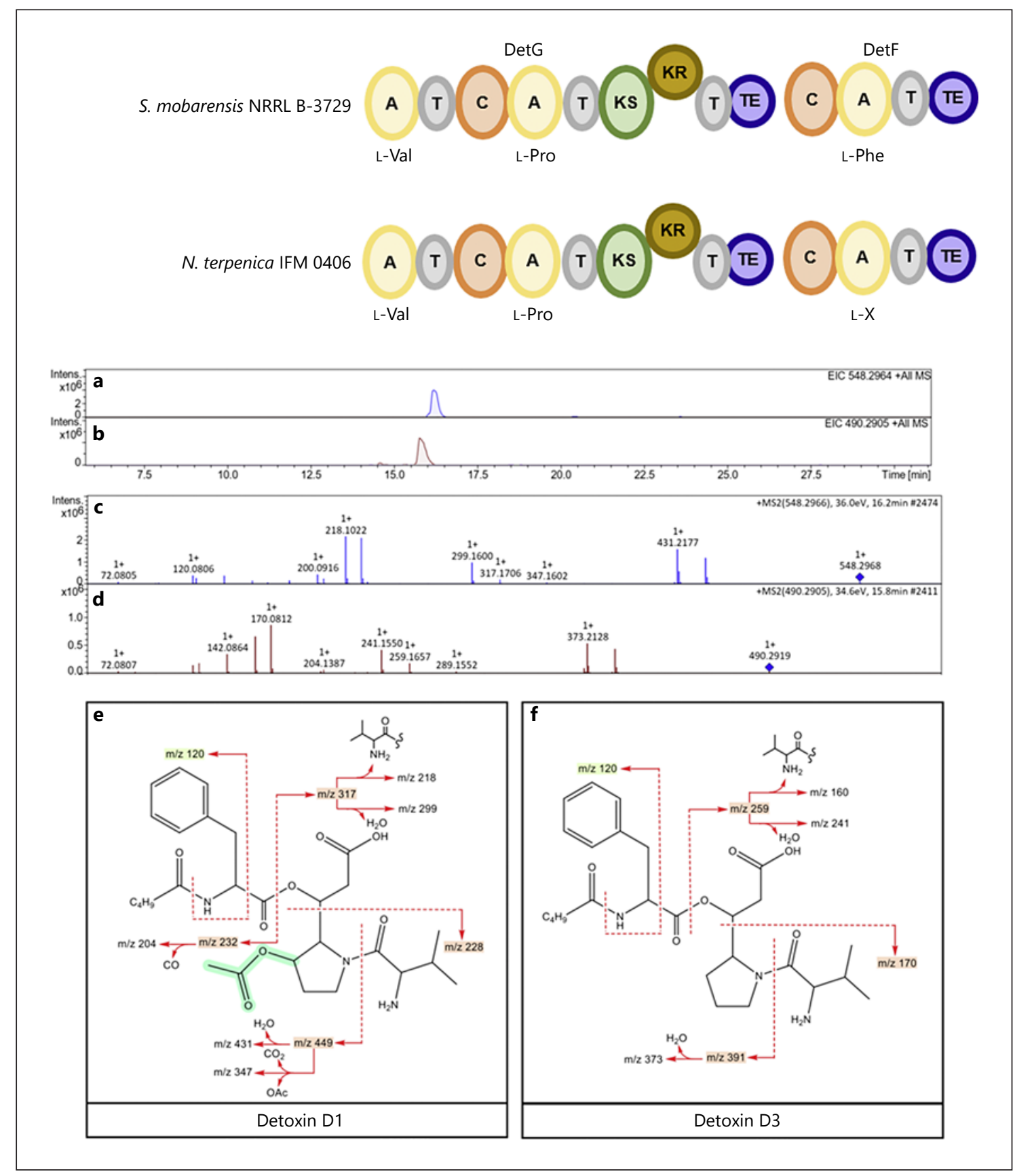

Fig. 8. Biosynthetic gene cluster of detoxin in S. mobarensis NRRL B-3729 and N. terpenica IFM 0406 and proof of production of detoxins by N. terpenica IFM 0406. LC/MS-extracted-ion chromatograms for the pseudomolecular masses of detoxin D1 (a) and detoxin D3 (b), respectively. From accurate mass measurements, the sum formulae $\mathrm{C}_{28} \mathrm{H}_{42} \mathrm{~N}_{3} \mathrm{O}_{8}$ (measured $m / z 548.2964[\mathrm{M}+\mathrm{H}]^{+}, \mathrm{D}$ $0.5 \mathrm{ppm}$ ) and $\mathrm{C}_{26} \mathrm{H}_{40} \mathrm{~N}_{3} \mathrm{O}_{6}$ (measured $m / z 490.2905[\mathrm{M}+\mathrm{H}]^{+}, \mathrm{D}$
$0.7 \mathrm{ppm}$ ) could be delineated, which were in perfect agreement with those of detoxin D1 and D3, respectively. Further tandem MS experiments $(\mathbf{c}, \mathbf{d})$ and their interpretation $(\mathbf{e}, \mathbf{f})$ corroborated the chemical structure of detoxin D1 (e) and detoxin D3 (f). The bolded green line (e) highlights the structural difference between detoxin D1 and D3. 


\section{Conclusion}

Natural products from Nocardia spp. are an important and continuously growing source for the discovery of diverse and effective bioactive molecules. The majority of the so far obtained secondary metabolites from Nocardia spp. are unique and exhibit a high degree of structural novelty; only occasionally the production of typical Streptomyces-derived compounds can be detected. To access the encoded chemistry, it is necessary to understand their natural triggers and to expand the genetic toolbox for $\mathrm{No}$ cardia. The function of small molecules in bacterial pathogenesis has been established for entomopathogenic and phytopathogenic bacteria, including diverse Photorhabdus, Xenorhabdus, Burkholderia, Pseudomonas and Streptomyces species. In many human pathogens, siderophores and cell wall components are also well described as virulence factors. An increasing number of examples now show that other specifically produced bioactive compounds can also have considerable impact on the progression and severity of bacterial infectious diseases [Maglangit et al., 2020]. Although Nocardia spp. are known as clinically relevant opportunistic pathogens, the role of their prolific secondary metabolism in nocardiosis is not understood. As we have summarized in this review, the chemical arsenal of Nocardia exhibits diverse cytotoxic, immunosuppressive and -modulatory bioactivities which could be relevant for their survival and dissemination in the human body. However, if such a link actually exists, it has to be experimentally corroborated. With in- creasing technical capabilities and interest in the field of chemical ecology and microbiology, the role of specialized molecules in Nocardia pathogenesis makes a fascinating subject for future investigations.

\section{Acknowledgement}

This work was supported by the Deutsche Forschungsgemeinschaft (DFG; GRK1708). We thank D. Männle for initial data acquisition.

\section{Conflict of Interest Statement}

The authors have no conflicts of interest to declare.

\section{Funding Sources}

This research was funded by the RTG 1708 "Molecular Principles of Bacterial Survival Strategies." We further acknowledge support by the Open Access Publishing Fund of the University of Tübingen.

H.S. gratefully acknowledges the Ministry of Higher Education of Egypt (MOHE) for funding.

\section{Author Contributions}

A.E., H.S., and L.K. generated and analyzed the data. A.E., H.S., L.K., and H.G. wrote the manuscript.

\section{References}

Anada M, Hanari T, Kakita K, Kurosaki Y, Katsuse K, Sunadoi Y, et al. Total synthesis of brasilicardins A and C. Org Lett. 2017;19(20): 5581-4.

Aoki H, Sakai H-I, Kohsaka M, Konomi T, Hosoda J, et al. Nocardicin A, a new monocyclic beta-lactam antibiotic. I. Discovery, isolation and characterization. J Antibiot (Tokyo). 1976;29(5):492-500.

Arai MA, Ebihara I, Makita Y, Hara Y, Yaguchi T, Ishibashi M. Isolation of nocobactin NAs as Notch signal inhibitors from Nocardia farcinica, a possibility of invasive evolution. J Antibiot (Tokyo). 2021;74(4):255-9.

Bai T, Zhang D, Lin S, Long Q, Wang Y, Ou H, et al. Operon for biosynthesis of lipstatin, the beta-lactone inhibitor of human pancreatic lipase. Appl Environ Microbiol. 2014;80(24): 7473-83.
Bai X, Guo H, Chen D, Yang Q, Tao J, Liu W. Isolation and structure determination of two new nosiheptide-type compounds provide insights into the function of the cytochrome P450 oxygenase NocV in nocathiacin biosynthesis. Org Chem Front. 2020;7(3):584-9.

Baltz RH. Genetic manipulation of secondary metabolite biosynthesis for improved production in Streptomyces and other actinomycetes. I Ind Microbiol Biotechnol. 2016;43(23):343-70.

Barka EA, Vatsa P, Sanchez L, Gaveau-Vaillant N, Jacquard C, Meier-Kolthoff JP, et al. Taxonomy, physiology, and natural products of Actinobacteria. Microbiol Mol Biol Rev. 2016; 80(1):1-43.

Barry DP, Beaman BL. Nocardia asteroides strain GUH-2 induces proteasome inhibition and apoptotic death of cultured cells. Res Microbiol. 2007;158(1):86-96.
Bauermeister A, Zucchi TD, Moraes LAB. Mass spectrometric approaches for the identification of anthracycline analogs produced by actinobacteria. J Mass Spectrom. 2016;51(6): 437-45.

Beaman BL. Mechanisms for the virulence of $\mathrm{No}^{-}$ cardia. In: Kado CI, Crosa JH, editors. Molecular Mechanisms of Bacterial Virulence. Developments in Plant Pathology, vol 3. Dordrecht: Springer; 1994. p. 561-72.

Beaman BL, Beaman L. Nocardia species: hostparasite relationships. Clin Microbiol Rev. 1994;7(2):213-64.

Bentley SD, Chater KF, Cerdeno-Tarraga AM, Challis GL, Thomson NR, James KD, et al. Complete genome sequence of the model actinomycete Streptomyces coelicolor A3(2) Nature. 2002;417(6885):141-7. 
Blin K, Shaw S, Kautsar SA, Medema MH, Weber T. The antiSMASH database version 3: increased taxonomic coverage and new query features for modular enzymes. Nucleic Acids Res. 2021;49(D1):D639-D43.

Bosello M, Zeyadi M, Kraas FI, Linne U, Xie X, Marahiel MA. Structural characterization of the heterobactin siderophores from Rhodococcus erythropolis PR4 and elucidation of their biosynthetic machinery. J Nat Prod. 2013;76(12):2282-90.

Brown-Elliott BA, Brown JM, Conville PS, Wallace RJ. Clinical and laboratory features of the Nocardia spp. based on current molecular taxonomy. Clin Microbiol Rev. 2006;19(2): 259-82.

Brown P, Dawson MJ. A perspective on the next generation of antibacterial agents derived by manipulation of natural products. Prog Med Chem. 2015;54:135-84.

Burkhart BJ, Schwalen CJ, Mann G, Naismith JH, Mitchell DA. YcaO-Dependent Posttranslational Amide Activation: Biosynthesis, Structure, and Function. Chem Rev. 2017;117(8): 5389-456.

Carrano CJ, Jordan M, Drechsel H, Schmid DG, Winkelmann G. Heterobactins: a new class of siderophores from Rhodococcus erythropolis IGTS8 containing both hydroxamate and catecholate donor groups. Biometals. 2001; 14(2):119-25.

Chen J, Frediansyah A, Männle D, Straetener J, Brötz-Oesterhelt $\mathrm{H}$, Ziemert N, et al. New Nocobactin Derivatives with Antimuscarinic Activity, Terpenibactins A-C, Revealed by Genome Mining of Nocardia terpenica IFM 0406. ChemBioChem. 2020;21(15):2205.

Chiu H-T, Weng C-P, Lin Y-C, Chen K-H. Target-specific identification and characterization of the putative gene cluster for brasilinolide biosynthesis revealing the mechanistic insights and combinatorial synthetic utility of 2-deoxy-1-fucose biosynthetic enzymes. Org Biomol Chem. 2016;14(6):1988-2006.

Chopra T, Banerjee S, Gupta S, Yadav G, Anand S, Surolia A, et al. Novel intermolecular iterative mechanism for biosynthesis of mycoketide catalyzed by a bimodular polyketide synthase. PLoS Biol. 2008;6(7):e163.

Conville PS, Brown-Elliott BA, Smith T, Zelazny AM. The complexities of Nocardia taxonomy and identification. J Clin Microbiol. 2018; 56(1).

Davidsen JM, Bartley DM, Townsend CA. Nonribosomal propeptide precursor in nocardicin A biosynthesis predicted from adenylation domain specificity dependent on the MbtH family protein NocI. J Am Chem Soc. 2013;135(5):1749-59.

Dhakal D, Chaudhary AK, Yi JS, Pokhrel AR, Shrestha B, Parajuli P, et al. Enhanced production of nargenicin A1 and creation of a novel derivative using a synthetic biology platform. Appl Microbiol Biotechnol. 2016a; 100(23):9917-31.
Dhakal D, Han JM, Mishra R, Pandey RP, Kim T-S, Rayamajhi V, et al. Characterization of tailoring steps of nargenicin A1 biosynthesis reveals a novel analogue with anticancer activities. ACS Chem Biol. 2020;15(6):1370-80.

Dhakal D, Kumar Jha A, Pokhrel A, Shrestha A, Sohng JK. Genetic manipulation of Nocardia species. Curr Protoc Microbiol. 2016b;40(1): 10F.2.1-10F.2.18

Dhakal D, Le TT, Pandey RP, Jha AK, Gurung R, Parajuli $P$, et al. Enhanced production of nargenicin $\mathrm{A}(1)$ and generation of novel glycosylated derivatives. Appl Biochem Biotechnol. 2015;175(6):2934-49.

Dhakal D, Rayamajhi V, Mishra R, Sohng JK. Bioactive molecules from Nocardia: diversity, bioactivities and biosynthesis. J Ind Microbiol Biotechnol. 2019;46(3-4):385-407.

Dhakal D, Sohng JK. Laboratory Maintenance of Nocardia Species. Curr Protoc Microbiol. 2015;39:10F.1.1-10F.1.8.

Dinesh K, Maharjan S, Dhakal D, Yoo JC, Sohng JK. Effect of different biosynthetic precursors on the production of nargenicin A1 from metabolically engineered Nocardia sp. CS682. J Microbiol Biotechnol. 2012;22(8):1127-32.

Doroghazi JR, Metcalf WW. Comparative genomics of actinomycetes with a focus on natural product biosynthetic genes. BMC Genomics. 2013;14(1):611-3.

Duggal SD, Chugh TD. Nocardiosis: A Neglected Disease. Med Princ Pract. 2020;29(6):514-23.

Dye C. After 2015: infectious diseases in a new era of health and development. Philos Trans R Soc Lond B Biol Sci. 2014;369(1645): 20130426

Gunsior M, Breazeale SD, Lind AJ, Ravel J, Janc JW, Townsend CA. The biosynthetic gene cluster for a monocyclic beta-lactam antibiotic, nocardicin A. Chem Biol. 2004 Jul;11(7): 927-38.

Han JM, Choi YS, Dhakal D, Sohng JK, Jung HJ. Novel Nargenicin A1 Analog Inhibits Angiogenesis by Downregulating the Endothelial VEGF/VEGFR2 Signaling and Tumoral HIF1a/VEGF Pathway. Biomedicines. 2020;8(8): 252.

Hara Y, Arai MA, Toume K, Masu H, Sato T, Komatsu K, et al. Coculture of a Pathogenic Actinomycete and Animal Cells To Produce Nocarjamide, a Cyclic Nonapeptide with Wnt Signal-Activating Effect. Org Lett. 2018; 20(18):5831-4.

Hashimoto M, Komori T, Kamiya T. Nocardicin A, a new monocyclic beta-lactam antibiotic II. Structure determination of nocardicins A and B. J Antibiot (Tokyo). 1976;29(9):890-901.

Hayashi Y, Matsuura N, Toshima H, Itoh N, Ishikawa J, Mikami Y, et al. Cloning of the gene cluster responsible for the biosynthesis of brasilicardin A, a unique diterpenoid. J Antibiot (Tokyo). 2008;61(3):164-74

Hideyuki S, Yasushi T, Katsukiyo Y, Yuzuru M, Jun'ichi K, Brasilinolide A. Brasilinolide A, new immunosuppressive macrolide from actinomycete Nocardia brasiliensis. Tetrahedron. 1996;52(27):9031-4.
Hochuli E, Kupfer E, Maurer R, Meister W, Mercadal Y, Schmidt K. Lipstatin, an inhibitor of pancreatic lipase, produced by Streptomyces toxytricini. II. Chemistry and structure elucidation. J Antibiot (Tokyo). 1987;40(8):108691.

Hoshino Y, Chiba K, Ishino K, Fukai T, Igarashi $\mathrm{Y}$, Yazawa K, et al. Identification of nocobactin NA biosynthetic gene clusters in Nocardia farcinica. J Bacteriol. 2011;193(2):441-8.

Hoshino Y, Mukai A, Yazawa K, Uno J, Ishikawa J, Ando A, et al. Transvalencin A, a thiazolidine zinc complex antibiotic produced by a clinical isolate of Nocardia transvalensis. I. Taxonomy, fermentation, isolation and biological activities. J Antibiot (Tokyo). 2004; 57(12):797-802.

Hosoda J, Tani N, Konomi T, Ohsawa S, Aoki H, Imanaka H. Incorporation of14C-Amino Acids into Nocardicin A by Growing Cells. Agric Biol Chem. 1977;41(10):2007-12.

Ji X, Zhang X, Sun L, Hou X, Song J, Tan X, et al. Mce1C and Mce1D facilitate N. farcinica invasion of host cells and suppress immune responses by inhibiting innate signaling pathways. Sci Rep. 2020;10(1):14908-13.

Katz L, Chen YY, Gonzalez R, Peterson TC, Zhao $\mathrm{H}$, Baltz RH. Synthetic biology advances and applications in the biotechnology industry: a perspective. J Ind Microbiol Biotechnol. 2018; 45(7):449-61.

Kaysser L. Built to bind: biosynthetic strategies for the formation of small-molecule protease inhibitors. Nat Prod Rep. 2019;36(12):165486.

Kim SH, Yoo JC, Kim TS. Nargenicin enhances 1,25-dihydroxyvitamin $\mathrm{D}(3)$ - and all-trans retinoic acid-induced leukemia cell differentiation via PKCbetaI/MAPK pathways. Biochem Pharmacol. 2009;77(11):1694-701.

Kobayashi J, Tsuda M, Nemoto A, Tanaka Y, Yazawa K, Mikami Y, et al. Brasilidine A, a new cytotoxic isonitrile-containing indole alkaloid from the actinomycete Nocardia brasiliensis. J Nat Prod. 1997;60(7):719-20.

Komaki H, Ichikawa N, Hosoyama A, TakahashiNakaguchi A, Matsuzawa T, Suzuki K-i, et al. Genome based analysis of type-I polyketide synthase and nonribosomal peptide synthetase gene clusters in seven strains of five representative Nocardia species. BMC Genomics. 2014;15(1):323.

Komaki H, Nemoto A, Tanaka Y, Takagi H, Yazawa K, Mikami Y, et al. Brasilicardin A, a new terpenoid antibiotic from pathogenic Nocardia brasiliensis: fermentation, isolation and biological activity. J Antibiot (Tokyo). 1999; 52(1):13-9.

Komatsu K, Tsuda M, Tanaka Y, Mikami Y, Kobayashi J. SAR studies of brasilicardin A for immunosuppressive and cytotoxic activities. Bioorg Med Chem. 2005;13(5):1507-13.

Komatsu K, Tsuda M, Tanaka Y, Mikami Y, Kobayashi J. Absolute stereochemistry of immunosuppressive macrolide brasilinolide $\mathrm{A}$ and its new congener brasilinolide C. J Org Chem. 2004;69(5):1535-41. 
Kuo J, Lynch SR, Liu CW, Xiao X, Khosla C. Partial in vitro reconstitution of an orphan polyketide synthase associated with clinical cases of nocardiosis. ACS Chem Biol. 2016; 11(9):2636-41.

LaMarche MJ, Leeds JA, Amaral A, Brewer JT, Bushell SM, Deng G, et al. Discovery of LFF571: an investigational agent for Clostridium difficile infection. J Med Chem. 2012; 55(5):2376-87.

Lee L-H, Goh B-H, Chan K-G. Editorial: Actinobacteria: Prolific producers of bioactive metabolites. Front Microbiol. 2020;11:1612.

Leet JE, Li W, Ax HA, Matson JA, Huang S, Huang R, et al. Nocathiacins, new thiazolyl peptide antibiotics from Nocardia sp. II. Isolation, characterization, and structure determination. J Antibiot (Tokyo). 2003;56(3): 232-42.

Leipoldt F, Santos-Aberturas J, Stegmann DP, Wolf F, Kulik A, Lacret R, et al. Warhead biosynthesis and the origin of structural diversity in hydroxamate metalloproteinase inhibitors. Nat Commun. 2017;8(1):1965.

Li W, Leet JE, Ax HA, Gustavson DR, Brown DM, Turner L, et al. Nocathiacins, new thiazolyl peptide antibiotics from Nocardia sp. I. Taxonomy, fermentation and biological activities. J Antibiot (Tokyo). 2003;56(3):226-31.

Loeffler DA, Camp DM, Qu S, Beaman BL, LeWitt PA. Characterization of dopaminedepleting activity of Nocardia asteroides strain GUH-2 culture filtrate on PC12 cells. Microb Pathog. 2004;37(2):73-85.

Luo Q, Hiessl S, Poehlein A, Daniel R, Steinbüchel A. Insights into the microbial degradation of rubber and gutta-percha by analysis of the complete genome of Nocardia nova SH22a. Appl Environ Microbiol. 2014a;80(13):3895-907.

Luo Q, Hiessl S, Steinbüchel A. Functional diversity of Nocardia in metabolism. Environ Microbiol. 2014b;16(1):29-48.

Luo Y, Enghiad B, Zhao H. New tools for reconstruction and heterologous expression of natural product biosynthetic gene clusters. Nat Prod Rep. 2016;33(2):174-82.

Maget-Dana R, Heitz F, Ptak M, Peypoux F, Guinand M. Bacterial lipopeptides induce ionconducting pores in planar bilayers. Biochem Biophys Res Commun. 1985;129(3):965-71.

Maglangit F, Yu Y, Deng H. Bacterial pathogens: threat or treat (a review on bioactive natural products from bacterial pathogens). Nat Prod Rep. 2021;38:782-821.

Mann J. Natural products as immunosuppressive agents. Nat Prod Rep. 2001;18(4):417-30.

Männle D, McKinnie SM, Mantri SS, Steinke K, Lu Z, Moore BS, et al. Comparative Genomics and Metabolomics in the Genus Nocardia. mSystems. 2020;5(3):e00125-20.

Matsunaga I, Sugita M. New insights into lipidic secondary metabolites in mycobacteria. Curr Chem Biol. 2011;5(1):52-63.

McNeil MM, Brown JM. The medically important aerobic actinomycetes: epidemiology and $\mathrm{mi}$ crobiology. Clin Microbiol Rev. 1994;7(3): 357-417.
Medema MH, Kottmann R, Yilmaz P, Cummings $\mathrm{M}$, Biggins JB, Blin K, et al. Minimum information about a biosynthetic gene cluster. Nat Chem Biol. 2015;11(9):625-31.

Miethke M, Marahiel MA. Siderophore-based iron acquisition and pathogen control. Microbiol Mol Biol Rev. 2007;71(3):413-51.

Mikami Y. Biological work on medically important Nocardia species. Actinomycetologica. 2007;21(1):46-51.

Mikami Y, Komaki H, Imai T, Yazawa K, Nemoto A, Tanaka $Y$, et al. A new antifungal macrolide component, brasilinolide $\mathrm{B}$, produced by Nocardia brasiliensis. J Antibiot (Tokyo). 2000;53(1):70-4.

Mikami Y, Yazawa K, Ohashi S, Maeda A, Akao $\mathrm{M}$, Ishibashi $\mathrm{M}$, et al. SO-75R1, a new mutactimycin derivative produced by Nocardia brasiliensis. J Antibiot (Tokyo). 1992;45(6): 995-7.

Mikami Y, Yazawa Y, Tanaka Y, Ritzau M, Gräfeb U. Isolation and Structure of Nocardiolactone, a New Dialkyl-Substituted $\beta$-Lactone from Pathogenic Nocardia Strains. Nat Prod Lett. 1999;13(4):277-84.

Mine Y, Nonoyama S, Kojo H, Fukada S, Nishida $M$, et al. Nocardicin A, a new monocyclic beta-lactam antibiotic V. In vivo evaluation. J Antibiot (Tokyo). 1977;30(11):932-7.

Momose I, Kinoshita N, Sawa R, Naganawa H, Iinuma $\mathrm{H}$, Hamada $\mathrm{M}$, et al. Nothramicin, a new anthracycline antibiotic from Nocardia sp. MJ896-43F17. J Antibiot (Tokyo). 1998; 51(2):130-5.

Montalban-Lopez M, Scott TA, Ramesh S, Rahman IR, van Heel AJ, Viel JH, et al. New developments in RiPP discovery, enzymology and engineering. Nat Prod Rep. 2021;38(1): 130-239.

Mukai A, Fukai T, Hoshino Y, Yazawa K, Harada K, Mikami Y. Nocardithiocin, a novel thiopeptide antibiotic, produced by pathogenic Nocardia pseudobrasiliensis IFM 0757. J Antibiot (Tokyo). 2009a;62(11):613-9.

Mukai A, Komaki H, Takagi M, Shin-ya K. Novel siderophore, JBIR-16, isolated from Nocardia tenerifensis NBRC 101015. J Antibiot. 2009b; 62(10):601-3

Mullane K, Lee C, Bressler A, Buitrago M, Weiss K, Dabovic K, et al. Multicenter, randomized clinical trial to compare the safety and efficacy of LFF571 and vancomycin for Clostridium difficile infections. Antimicrob Agents Chemother. 2015;59(3):1435-40.

Navarro-Muñoz JC, Selem-Mojica N, Mullowney MW, Kautsar SA, Tryon JH, Parkinson EI, et al. A computational framework to explore large-scale biosynthetic diversity. Nat Chem Biol. 2020;16(1):60-8.

Nemoto A, Tanaka Y, Karasaki Y, Komaki H, Yazawa K, Mikami Y, et al. New benz[alpha] anthraquinone antibiotics from Nocardia brasiliensis. I. Producing strain, isolation and biological activities of the antibiotics. J Antibiot (Tokyo). 1997 Jan;50(1):18-21.
Netzker T, Flak M, Krespach MK, Stroe MC, Weber J, Schroeckh V, et al. Microbial interactions trigger the production of antibiotics. Curr Opin Microbiol. 2018;45:117-23.

Nishida M, Mine Y, Nonoyama S, Kojo H. Nocardicin $\mathrm{A}$, a new monocyclic beta-lactam antibiotic III. In vitro evaluation. J Antibiot (Tokyo). 1977;30(11):917-25.

Park C, Kwon DH, Hwang SJ, Han MH, Jeong JW, Hong SH, et al. Protective Effects of Nargenicin A1 against Tacrolimus-Induced Oxidative Stress in Hirame Natural Embryo Cells. Int J Environ Res Public Health. 2019;16(6): 1044.

Pidot SJ, Herisse M, Sharkey L, Atkin L, Porter JL, Seemann T, et al. Biosynthesis and EtherBridge Formation in Nargenicin Macrolides. Angew Chem Int Ed Engl. 2019;58(12):39964001.

Portevin D, de Sousa-D'Auria C, Houssin C, Grimaldi C, Chami M, Daffé $M$, et al. A polyketide synthase catalyzes the last condensation step of mycolic acid biosynthesis in mycobacteria and related organisms. Proc Natl Acad Sci U S A. 2004;101(1):314-9.

Robinson SL, Christenson JK, Wackett LP. Biosynthesis and chemical diversity of $\beta$-lactone natural products. Nat Prod Rep. 2019;36(3): 458-75.

Robinson SL, Terlouw BR, Smith MD, Pidot SJ, Stinear TP, Medema MH, et al. Global analysis of adenylate-forming enzymes reveals $\beta$-lactone biosynthesis pathway in pathogenic Nocardia. J Biol Chem. 2020;295(44):1482639.

Ryll R, Kumazawa Y, Yano I. Immunological Properties of Trehalose Dimycolate (Cord Factor) and Other Mycotic Acid-Containing Glycolipids - A Review. Microbiol Immunol. 2001;45(12):801-11.

Sakai K, Komaki H, Gonoi T. Identification and Functional Analysis of the Nocardithiocin Gene Cluster in Nocardia pseudobrasiliensis. PLoS One. 2015;10(11):e0143264.

Schneider K, Rose I, Vikineswary S, Jones AL, Goodfellow M, Nicholson G, et al. Nocardichelins A and B, siderophores from Nocardia strain acta 3026. J Nat Prod. 2007;70(6):9325.

Schorn M, Zettler J, Noel JP, Dorrestein PC, Moore BS, Kaysser L. Genetic basis for the biosynthesis of the pharmaceutically important class of epoxyketone proteasome inhibitors. ACS Chem Biol. 2014;9(1):301-9.

Schwarz PN, Buchmann A, Roller L, Kulik A, Gross H, Wohlleben W, et al. The immunosuppressant brasilicardin: determination of the biosynthetic gene cluster in the heterologous host Amycolatopsis japonicum. Biotechnol J. 2018a;13(2):1700527.

Schwarz PN, Roller L, Kulik A, Wohlleben W, Stegmann E. Engineering metabolic pathways in Amycolatopsis japonicum for the optimization of the precursor supply for heterologous brasilicardin congeners production Synth Syst Biotechnol. 2018b;3(1):56-63. 
Shigemori H, Komaki H, Yazawa K, Mikami Y, Nemoto A, Tanaka Y, et al. Biosynthesis of diterpenoid moiety of brasilicardin A via non-mevalonate pathway in Nocardia brasiliensis. Tetrahedron Lett. 1999;40(23):4353-4.

Shigemori H, Komaki H, Yazawa K, Mikami Y, Nemoto A, Tanaka Y, et al. Brasilicardin A. A Novel Tricyclic Metabolite with Potent Immunosuppressive Activity from Actinomycete Nocardiabrasiliensis. J Org Chem. 1998; 63(20):6900-4.

Shimazu A, Yamaki H, Furihata K, Endo T, Otake $\mathrm{N}$, Yonehara Y. Effect of detoxin D on blasticidin $S$ uptake in Bacillus cereus. Experientia. 1981;37(4):365-6.

Sritharan M. Iron as a candidate in virulence and pathogenesis in mycobacteria and other microorganisms. World J Microbiol Biotechnol. 2000;16(8-9):769-80.

Stinear TP, Mve-Obiang A, Small PL, Frigui W, Pryor MJ, Brosch R, et al. Giant plasmid-encoded polyketide synthases produce the macrolide toxin of Mycobacterium ulcerans. Proc Natl Acad Sci U S A. 2004;101(5):1345-9.

Tanaka Y, Graefe U, Yazawa K, Mikami Y. Production of nocardicyclins by clinical isolates of Nocardia pseudobrasiliensis and in vivo antitumor activity of the antibiotic. J Antibiot (Tokyo). 1998;51(6):589-91.

Tanaka Y, Grafe U, Yazawa K, Mikami Y, Ritzau M. Nocardicyclins A and B: new anthracycline antibiotics produced by Nocardia pseudobrasiliensis. J Antibiot (Tokyo). 1997a; 50(10):822-7.

Tanaka Y, Komaki H, Yazawa K, Mikami Y, Nemoto A, Tojyo T, et al. Brasilinolide A, a new macrolide antibiotic produced by Nocardia brasiliensis: producing strain, isolation and biological activity. J Antibiot (Tokyo). 1997b;50(12):1036-41.

Townsend CA, Brown AM. Nocardicin A biosynthesis: stereochemical course of monocyclic beta-lactam formation. J Am Chem Soc. 1982; 104(6):1748-50.
Townsend CA, Brown AM. Nocardicin A: biosynthetic experiments with amino acid precursors. J Am Chem Soc. 1983;105(4):913-8.

Townsend CA, Brown AM, Nguyen LT. Nocardicin A: stereochemical and biomimetic studies of monocyclic $\beta$-lactam formation. J Am Chem Soc. 1983;105(4):919-27.

Townsend CA, Salituro GM. Fate of [15N]-p-hydroxyphenyl)glycine in nocardicin a biosynthesis. J Chem Soc Chem Commun. 1984(24): 1631-2.

Tsuda M, Nemoto A, Komaki H, Tanaka Y, Yazawa K, Mikami Y, et al. Nocarasins $\mathrm{A}-\mathrm{C}$ and Brasiliquinone D, New Metabolites from the ActinomyceteNocardiabrasiliensis. J Nat Prod. 1999;62(12):1640-2.

Usui T, Nagumo Y, Watanabe A, Kubota T, Komatsu K, Kobayashi J, et al. Brasilicardin A, a natural immunosuppressant, targets amino acid transport system L. Chem Biol. 2006; 13(11):1153-60.

Vera-Cabrera L, Ortiz-Lopez R, Elizondo-Gonzalez R, Ocampo-Candiani J. Complete genome sequence analysis of Nocardia brasiliensis HUJEG-1 reveals a saprobic lifestyle and the genes needed for human pathogenesis. PLoS One. 2013;8(6):e65425.

Walsh CT, Fischbach MA. Natural products version 2.0: connecting genes to molecules. J Am Chem Soc. 2010;132(8):2469-93.

Wiebach V, Mainz A, Siegert MJ, Jungmann NA, Lesquame G, Tirat $\mathrm{S}$, et al. The anti-staphylococcal lipolanthines are ribosomally synthesized lipopeptides. Nat Chem Biol. 2018; 14(7):652-4.

Wilson JW. Nocardiosis: updates and clinical overview. Mayo Clin Proc. 2012;87:403-7.

Wohlleben W, Mast Y, Muth G, Röttgen M, Stegmann E, Weber T. Synthetic biology of secondary metabolite biosynthesis in actinomycetes: engineering precursor supply as a way to optimize antibiotic production. FEBS Lett. 2012;586(15):2171-6.
Wolf F, Bauer JS, Bendel TM, Kulik A, Kalinowski J, Gross $\mathrm{H}$, et al. Biosynthesis of the $\beta$-Lactone Proteasome Inhibitors Belactosin and Cystargolide. Angew Chem Int Ed Engl. 2017;56(23):6665-8.

Wyche TP, Hou Y, Vazquez-Rivera E, Braun D, Bugni TS. Peptidolipins B-F, antibacterial lipopeptides from an ascidian-derived Nocardia sp. J Nat Prod. 2012;75(4):735-40.

Yonehara H, Seto H, Aizawa S, Hidaka T, Shimazu A, Otake N. The detoxin complex, selective antagonists of blasticidin S. J Antibiot (Tokyo). 1968;21(5):369-70.

Yoo JC, Cho HS, Park E, Park JA, Kim S, Kim DK, et al. Nargenicin attenuates lipopolysaccharide-induced inflammatory responses in BV-2 cells. Neuroreport. 2009;20(11):100712.

Yu J, Tran V, Li M, Huang X, Niu C, Wang D, et al. Both phthiocerol dimycocerosates and phenolic glycolipids are required for virulence of Mycobacterium marinum. Infect Immun. 2012;80(4):1381-9.

Yuet KP, Liu CW, Lynch SR, Kuo J, Michaels W, Lee RB, et al. Complete Reconstitution and Deorphanization of the $3 \mathrm{MDa}$ NocardiosisAssociated Polyketide Synthase. J Am Chem Soc. 2020;142(13):5952-7.

Zettler J, Zubeil F, Kulik A, Grond S, Kaysser L. Epoxomicin and Eponemycin Biosynthesis Involves gem-Dimethylation and an AcylCoA Dehydrogenase-Like Enzyme. Chembiochem. 2016;17(9):792-8.

Zipperer A, Konnerth MC, Laux C, Berscheid A, Janek D, Weidenmaier C, et al. Human commensals producing a novel antibiotic impair pathogen colonization. Nature. 2016; 535(7613):511-6.

Zoropogui A, Pujic P, Normand P, Barbe V, Belli $\mathrm{P}$, Graindorge A, et al. The Nocardia cyriacigeorgica GUH-2 genome shows ongoing adaptation of an environmental Actinobacteria to a pathogen's lifestyle. BMC Genomics. 2013;14(1):286-18 